\title{
Perceforest. Complément. Variantes inédites, publiées par G. Roussineau
}

\section{Maria Colombo Timelli}

\section{(2) OpenEdition}

10 Journals

\section{Édition électronique}

URL : https://journals.openedition.org/studifrancesi/20917

DOI : 10.4000/studifrancesi.20917

ISSN : 2427-5856

Éditeur

Rosenberg \& Sellier

\section{Édition imprimée}

Date de publication : 1 décembre 2019

Pagination : 553

ISSN : 0039-2944

\section{Référence électronique}

Maria Colombo Timelli, «Perceforest. Complément. Variantes inédites, publiées par G. Roussineau », Studi Francesi [En ligne], 189 (LXIII | III) | 2019, mis en ligne le 01 mars 2020, consulté le 11 novembre 2021. URL : http://journals.openedition.org/studifrancesi/20917 ; DOI : https://doi.org/10.4000/ studifrancesi.20917

Ce document a été généré automatiquement le 11 novembre 2021.

\section{(c)}

Studi Francesi è distribuita con Licenza Creative Commons Attribuzione - Non commerciale - Non opere derivate 4.0 Internazionale. 


\title{
Perceforest. Complément. Variantes inédites, publiées par G. Roussineau
}

\author{
Maria Colombo Timelli
}

\section{RÉFÉRENCE}

Perceforest. Complément. Variantes inédites, publiées par G. Roussineau, Genève, Droz, 2018, «Textes Littéraires Français» 647, 625 pp.

Disons-le tout de suite, le titre de ce volume est trompeur de par sa modestie: G.R. a fait beaucoup plus, et beaucoup mieux, que d'offrir les variantes les plus significatives du manuscrit $C$ de Perceforest, copié par David Aubert, pour les premiers volumes parus de son édition (Troisième partie, tomes I, 1988, et II, 1991; Quatrième partie, 1987). L'Introduction (pp. V-XLVIII) offre d'abord une précieuse synthèse sur les rapports entre les manuscrits - $A B$ d'un côté, $C$ de l'autre - pour la section qui correspond à la traduction de l'Histoira regum Britannie de Geoffroy de Monmouth (§ 2-78: la version de C est éditée intégralement, accompagnée d'un apparat de notes, aux pp.5-63); les variantes examinées confirment que les trois manuscrits ne dérivent pas l'un des autres, et prouvent au contraire qu'ils s'appuient sur une traduction française intermédiaire, non conservée. Suit l'examen des variantes de la Quatrième partie, qui deviennent plus nombreuses et plus importantes vers la fin de cette section: David Aubert introduit des dialogues, des passages descriptifs, des détails, des réflexions, des renvois internes, mais il lui arrive - comme la critique l'a souvent souligné - d'allonger le récit sans apporter aucune information nouvelle, voire d'insérer des erreurs. Ces variantes confirment elles aussi l'existence d'une rédaction française perdue, que $A B$ ont plutôt tendance à abréger, et que $C$ amplifie volontiers. Quelques remarques sur la langue de $C$ concernent la graphie, la morphologie / syntaxe (marquée par des traits de la scripta du Nord de la France), et surtout le lexique: mots absents dans les dictionnaires; mots, locutions, sens rares; acceptions peu attestées. Une liste des 
proverbes et expressions sentencieuses - avec renvoi, le cas échéant, aux répertoires d'usage: Morawski et Hassell - complète l'analyse.

2 Les variantes de la Troisième partie occupent les pp. 65-77 (Tome I) et 79-169 (Tome II); celles de la Quatrième partie, de plus en plus nombreuses et souvent très longues, se lisent aux pp. 171-623: David Aubert réécrivant des passages entiers, ces pages rendront un grand service non seulement aux lecteurs de Perceforest, mais aussi à tous ceux qui s'intéressent à ses procédés de transcription et, plus amplement, à la production et à la transmission des textes dans la seconde moitié $d u \mathrm{Xv}^{\mathrm{e}}$ siècle. 